\title{
Simulation as a Tool for Process Optimization in a Manufacturing Company
}

\author{
Zdenka Vidrova ${ }^{1, *}$, Zoltan Bohus ${ }^{2}$, and Peter Adamko ${ }^{3}$ \\ ${ }^{1}$ University of Zilina, Faculty of Operation and Economics of Transport and Communications, \\ Department of Economics, Univerzitna 1, 01026 Zilina, Slovakia \\ ${ }^{2}$ SOVA Digital a. s., Bojnicka 3, 83104 Bratislava, Slovakia \\ 3University of Zilina, Faculty of Operation and Economics of Transport and Communications, \\ Department of Quantitative Methods and Economic Informatics, Univerzitna 1, 01026 Zilina, \\ Slovakia
}

\begin{abstract}
.
Research background: In today's global world and many major market players, companies are forced to streamline and optimize their processes. They can use many methods for this purpose. One of the modern and innovative methods is process simulation. Simulation is experimenting with a computer model of a real production system in order to optimize the production process.

Purpose of the article: The purpose of this article is to point out how it is possible to optimize processes in a manufacturing plant using a simulation tool.

Methods: The main methods used were mainly method of analysis and simulation software Tecnomatix Plant Simulation, version 15.0.5 from Siemens company. The authors used the method of analysis both in the processing of the theoretical basis of the problem, as well as in the analysis of processes in the manufacturing company. This analysis provided important information inputs for creating a simulation model that reflects the current state of material flows in the company.

Findings \& Value added: The results were obtained based on performed experiments with the created initial model of the current state of material flows. These experiments were performed using a tool of genetic algorithms that are part of the simulation software. The parameter that was assessed in the individual experiments was the production time of the entire production plan. Based on the process simulation, it was possible to reduce this time, which increased the production efficiency and throughput of material flows in the production plant.
\end{abstract}

Keywords: simulation; optimization of processes; genetic algorithms; model of logistics flows; innovation

JEL Classification: C53; C61; C63; D24; O30; L6.

${ }^{*}$ Corresponding author: zdenka.vidrova@,fpedas.uniza.sk 


\section{Introduction}

There is no denying that today's digital world is pushing businesses to use advanced simulation tools in business practice. They are important at every level of the product life cycle, especially in the process of design, analysis and optimization of production and logistics systems. The great advantage of these tools is that they allow changes in existing production systems by experimentation [1]. Therefore, simulation and modelling will become an integral part of the planning and control of the processes of the factories of the future [2]. [3] argue that companies rely on the power of simulation every day to gain a competitive advantage in their market.

The popularity of simulation is constantly increasing, mainly due to its wide use for analysis and modelling of systems in various application areas, such as production or business processes [4]. The simulation has its irreplaceable place in almost every area and the possibilities of use are wide. It is a tool for a better understanding of process behaviour and the search for optimal solutions [5]. It is modelling and simulation that give managers the opportunity to test of how the proposed logistics system will work and evaluate its optimality based on the assessment of costs and performance parameters [6].

Simulation of logistics systems is one of the statistical-experimental methods. Its basic principle consists in a simplified presentation of a real system through a simulation model. The simulation model describes only those properties of the real system that interest us in terms of the problem. After verification of the validity of the model, a set of simulation experiments is performed with the model. Individual variants of simulation experiments represent individual proposals, "improvements" of the simulated system. It is necessary to realize that the results obtained by the simulation are probable quantities and it is necessary to work with them accordingly $[7,8]$. Although the simulated system should reflect the real one, the authors [9] argue that there are differences between these two systems, which only become apparent when solving both.

The simulation in logistics can be used, for example, in the case [10,11]:

- analyses of the performance of the production and logistics system (elimination of bottlenecks, optimization of running times and stocks, determination of the system's performance limits),

- dimensioning of transport and handling systems,

- optimization of picking and shipping processes,

- inventory optimization,

- examination of variants of control and layout systems (e.g. push and pull systems),

- balancing production and assembly lines.

Currently, there is strong software support for the simulation of production and logistics systems, which allows the entire simulation process to be visualized and to define virtually any configuration of the output message from simulation experiments [12]. For the needs of solving the study we selected, we chose simulation software from Siemens based on the recommendations of experts in this field.

\section{Methods}

The research took place in a large manufacturing company based in the Slovak Republic, which is engaged in the production of rolling bearings in the segments of the automotive, aerospace and textile industries. In the analysis and simulation, we focused on selected bearings designed for the automotive industry, which form the main segment of the company's sales. 


\subsection{Process sheets and flow charts}

The first and necessary step for obtaining relevant data was the analysis of the production process, respectively, material flow, which was built mainly on its observation. We have chosen process sheets and flow diagrams as complementary tools for observing the production process. Within these tools, it was necessary to distinguish individual types of operations within the production process (production logistics). They are shown in the following table together with a more detailed description.

Table 1. Types of activities in manufacturing

\begin{tabular}{|c|c|}
\hline Type of activity & Characteristics \\
\hline Operation & Technological operation, assembly, change of physical or chemical properties \\
\hline Transportation & Move from one place to another \\
\hline Manipulation & The material or object is prepared or modified for operation, storage, \\
inspection, transport
\end{tabular}

Source: [6]

Making process sheets in combination with flow charts allowed us to get a picture of the material flow model in this company. This analysis revealed the current "problems" of the company. We have found that before a finished bearing is formed, the material has to travel really long distances, which also leads to time losses. From the observation of the production process and its analysis, we can also define the causes of these problems. The most important thing is to define the main problem, from which many others arise - the continuous production time of one type of bearing is up to 21 days. This information was confirmed to us by the chief technologist.

Based on a thorough analysis, we were able to define the factors that led to this problem, respectively, they act directly on the logistical arrangement of the material flow. First, we start from the layout of the workplace, i.e. the arrangement of machines and equipment in production halls. When we look at the production of this type of bearing, which by the way belongs to the most numerous group in the manufactured portfolio, machines and equipment according to the sequence of individual operations are not located in one production hall, so there are huge material transfers, which further directly affects material handling and also and related time losses. Another factor, that greatly affects the production time of the bearing, is the capacity of individual machines and equipment. The problem is that while the machine can process many parts in the first operation, these parts must "wait" before further operations, which are performed on machines with lower capacity. This creates downtime for individual semi-finished products and thus also for material flow.

\subsection{Creating a simulation model}

Obtaining this data was necessary to create a model of the logistical arrangement of the material flow. For this purpose, we have chosen a very progressive and innovative tool Tecnomatix Plant Simulation software, version 15.0.5. from Siemens, the use of which in Slovak companies is not so widespread. This software tool is designed to simulate discrete events and helps to create complex digital models of different types of systems, e.g. logistical, and allows the investigation of their individual characteristics, for their optimization and evaluation. To achieve the most holistic approach to the real-time simulation model, the SimTalk programming language can be used and individual blocks of the model can be programmed according to user requirements [13]. Some authors have 
decided to extend the usefulness of TPS software, for example by simulating a morphological creative method [14].

Output data from the analysis of the production process were used as input data to the simulation model, mainly:

- technological process of production,

- sequence of production operations,

- assignment of specific machines to given production operations,

- duration of production operations,

- recasting time of machines,

- arrangement of machines within the layout of the production plant,

- the need for unit staff,

- inputs of the production process,

- outputs of the production process,

- production plans (annual, monthly, weekly, daily).

For the purpose of creating a simulation model, we selected three groups of bearings, namely K2291, R2242 and R2021. Each of these types has a similar production process, which means that before the finished bearing is created, its individual components must be produced - shaft, outer ring, cages. Subsequently, these components are assembled into the bearing. We selected these types as a representative sample because they are produced in the largest batches and can therefore save considerable costs.

To create the structure of the simulation model and a study for a given implementation of the material flow, it is necessary to use specific elements offered by the simulation software. For the purposes of our study, we chose the following elements, which we further worked with:

- representation of material flow,

- representation of information flow,

- in-process control

- resources (input material / raw material),

- movement of elements within the model,

- connectors,

- entry entity,

- output entity,

- work group,

- statistical report of production,

- production routes, etc.

The model that was created represents the current state of material flows. If we want to change this state and find out how it affects the overall production, it is possible to change the following parameters with respect to the real state:

- number of employees (operators, logisticians),

- production plan and production batch sizes - in this case, genetic algorithms can be used that generate different combinations of production batches and look for the best possible solution,

- variability of production, etc.

Due to the limited scope of the article, we do not provide an extensive preview of the material flow model drawing as output from the Tecnomatix Plant Simulation software.

\subsection{AutoCad}

When analyzing the production process, we also worked with the AutoCad program, which is mainly used for designing production halls. The advantage of the simulation software is also the possibility to pair it with the AutoCad program, i.e. we will have a precisely 
displayed production hall in the simulation space. Then all you must do is set AutoCad to the real scale of the production plant. This setting eliminates the need to manually measure the distances of individual machines and the length of the material flow. Thanks to the pairing with the AutoCAD program, the simulation software can calculate it itself based on the location of individual work paths in the simulation space. We analysed the K2291 bearing before using the simulation software, and in this case, we measured these distances manually and based on this analysis we were able to create process sheets and flow charts.

In some cases, however, it is not possible to use AutoCad in simulation software, because the original project documentation is completely different from reality. This means that to simulate, we need to get a digital 3D model of the real state in production. Practically the only meaningful way is $3 \mathrm{D}$ scanning. A point cloud is a set of data in the coordinate system $(\mathrm{x}, \mathrm{y}, \mathrm{z})$ that represents the outer surface of a scanned object. 3D Point Cloud models are generated from these points. By scanning existing companies, cloud points are created, on the basis of which entire 3D models of the company (production hall) with its complete structure are created, including machines, equipment, columns, walls, roads, etc. Business models can be directly integrated into the 3D Plant Simulation environment [15].

\subsection{Genetic algorithms}

Within the simulation software it is possible to use several methods and tools, thanks to which it is possible to optimize processes. For example, the authors [16] used the Value Stream Mapping tool in their research as part of the functions of simulation software. We decided to use genetic algorithms. The function that we decided to monitor and at the same time minimize was the continuous production time of three types of bearings. The input to the genetic algorithms was the production plan and thus the size of the production batches of individual components. Using genetic algorithms, it was possible to create a huge number of combinations and thus select the best (optimal) variant according to predetermined parameters.

\section{Results}

After the end of production within the simulation model, we can look at the production statistics, which will provide the company with relevant data. Given the size range of the tables, we will not list them in the article, but we will mention what statistics this tool can provide us:

- waiting times,

- process times during the day,

- filling the capacities of individual machines,

- properties of material flows,

- total working time,

- total production time,

- distance travelled by individual workers,

- machine setting time,

- process blocking time,

- downtime,

- occupancy of employees,

- occupancy of machines, etc. 
We also used these statistics to change the conditions of the model, which could be applied in real production and it would be possible to improve the overall results of the production process and its efficiency, respectively, optimize the production process. In total, we tried three simulations, in which we wanted to improve (optimize) the current, real state. The function we wanted to minimize was the total production time of the selected three types of bearings. At present, the company also must deal with this problem. For the target variable, we could also choose, for example, the cost of recasting, the length of the material flow, the handling time, the number of machines, etc.

\subsection{Simulation no. 1}

Our goal was to reduce the total production time of three selected types of bearings during the simulation. The total production time is greatly affected by the production technology (sequence and duration of operations on individual machines) and the layout of the company - long distances between individual machines extend the handling time. Since changing these factors is not easy and would require time, we tried to come up with another solution. The length of production time is also affected by the arrangement and size of production batches. This means that we started from the company's current production plan and tried to change it according to the requirements of optimization using the genetic algorithm tool, which is part of the TPS software. For the subject of optimization (improvement), we chose the total production time.

We decided to use the real production plan for the month of May 2020 of three selected types of bearings, also individual bearing components. The sizes of the production batches of shafts and outer rings must be identical, as they become part of the finished bearing when assembled in one piece. The material flow of each component is marked with a different colour in the simulation model for better identification.

The total number of batches produced for all three types of bearings at the end of production had to be 53 - the total number of 53,000 bearings, as one batch contains 1,000 pieces. After running the simulation, which reflected the real conditions in the company, the original production plan was completed in 37,146 days. During this time, 53000 pieces of bearings were produced.

When entering the conditions for starting genetic algorithms, it is necessary to choose whether we are looking for a minimum or a maximum of a function; number of generations and size of generation. Each generation learns from the previous one. The more generations and the larger the generation size we choose, the more time consuming the background calculations will take. On the other hand, it is better to choose a higher number, because there is a greater chance that individual generations will learn more and achieve an optimal result, which would not have happened with a small number of generations. After the advice of an expert from practice, we chose 30 generations and the size of the generation also 30. Based on the number of generations and the size of generations, we can find out how many simulations will be performed according to the following formula: number of simulation runs $=$ observations per individual $*$ (generation size $+2 *$ generation size $*$ (number of generations - 1)).

The genetic algorithm tool changed the order of batches within the production plan to find the lowest production time. The best production plan, of all simulated ones, was fulfilled in 30.54 days. By rearranging the production batches, we could therefore save almost seven days. However, we must note that the sizes of the production batches did not change due to the real situation, only the order of these batches changed. In this case, the recasting time of individual machines also played a big role. 


\subsection{Simulation no. 2}

The principle of the second simulation is very similar to the first. The difference is that in this case the size of production batches also changed - we tried to intuitively combine small production batches into larger units. This would also reduce the number of recasts of individual machines. We applied the tool genetic algorithms to the production plan modified by us and again we were looking for the best solution - the lowest number of production days.

Such a production plan would be completed in 30,536 days, i.e. a little shorter than in simulation 1. The following graphs can also be used to present the results from the genetic algorithms tool. In the first case, the $\mathrm{x}$-axis shows the number of generations and the $y$-axis the number of production days. Here we can observe that generations have learned from each other and gradually achieved the best possible result under these conditions.

\section{Evolution of the fitness values of the generations}

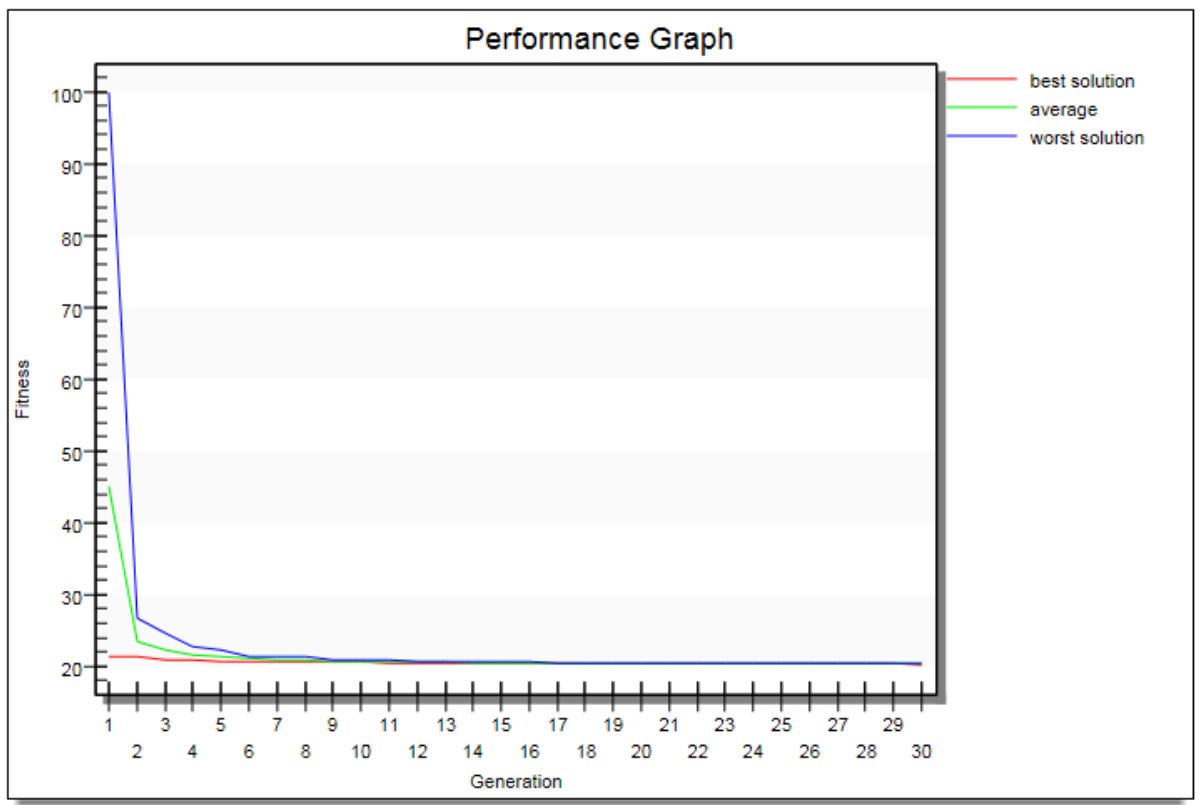

Fig, 1. Solution development using genetic algorithms (30 generations).

Source: output from TPS

The second graph shows simulations within the last, thirtieth generation, where the $\mathrm{x}$ axis shows the size of the generation and the y-axis the number of days of production. 
Generation 30

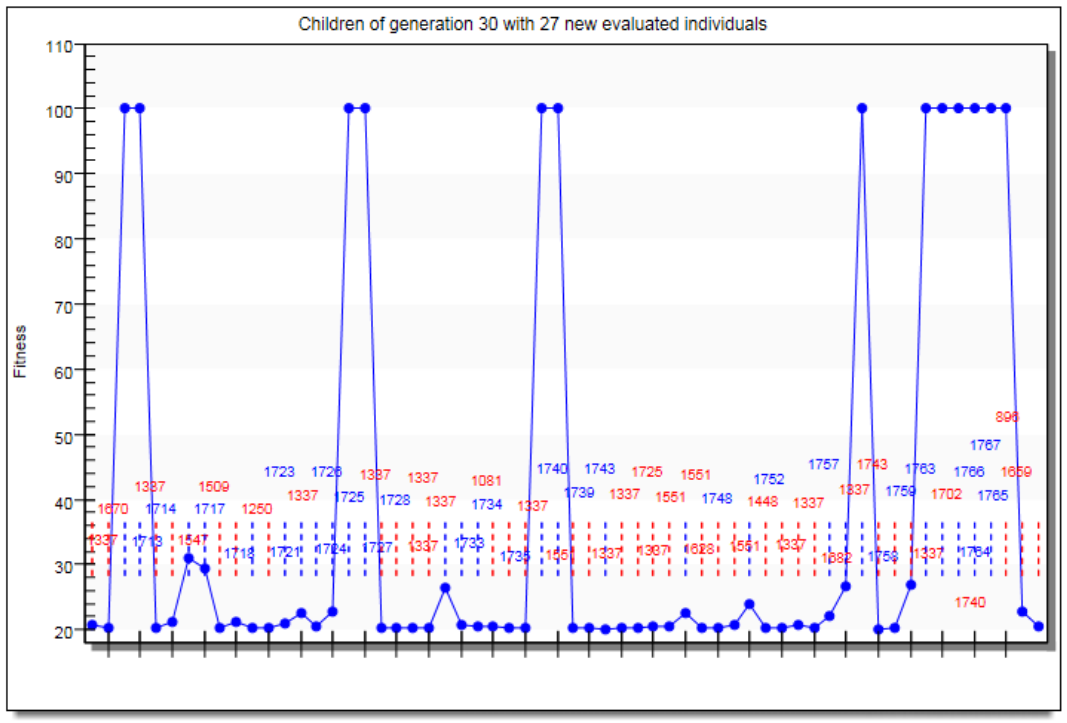

Fig. 2. Solution development in the Generation 30.

Source: output from TPS

\subsection{Simulation no. 3}

Simulation number 3 will be based on the results of simulation no. 2 but will be different from the previous ones. We therefore chose the best rated plan from simulation number 2 as our initial production plan. In this case, we did not use genetic algorithms to find the best solution, but we worked with bottlenecks. Every system is as strong as its bottleneck. The capacity imbalance of the machines is a persistent problem in this production plant. In the detailed analysis, we found that there are mainly two bottlenecks in the production plant, namely the BDE25CNC and KMA101E machines. This problem can be eliminated in a simulation environment by changing the number of machine dimensions - from one dimension to 2. This means that in a simulation environment we test what results will be achieved if these machines process twice as many components in the same time - from one machine would two machines working in parallel were created. This seemingly simple change brought very surprising results. We found that if the problem of these two bottlenecks were eliminated, 53000 bearings would be produced in as little as 22,957 days. If we compare this result with the real situation in the company, the reduction of production time is up to almost $39 \%$.

The advantage of the simulation is just saving time and money, as well as other indicators, as changes do not need to be tested first on real production and observe the results. It is possible to try it first in a simulation program and only then apply it to real production in case of better results after the change. 


\section{Discussions}

Based on the simulation software, we created a model of the logistics arrangement of the material flow in a specific manufacturing company. We decided to create a model of the production of three types of bearings, which are among the most widely produced. We consider the human and financial factor to be the biggest limits when working with the Tecnomatix Plant Simulation 15. In this software it is possible to use several functions and methods and simulate virtually any type of production. However, the quality of the simulation results depends very much on the user of this software. Working in this software is demanding and requires knowledge of the SimTalk programming language, which is specific only to the software. The company obtains a lifetime license by purchasing the software, but this amount may not be acceptable to every business. However, if companies want to simulate their processes, they do not have to buy this software. All they must do is turn to an expert in the field, who will process the project for them according to their specific requirements.

The contribution is an output of the project VEGA 1/0619/20 Fundamental research of quantitative and qualitative determinants of enterprise innovation potential and innovation performance in relation to increasing its competitiveness.

\section{References}

1. Trebuna, P., Pekarcikova, M., Petrik, M. (2018). Application of tecnomatix process simulate for optimisation of logistics flows. Acta Montanistica Slovaca, 23(4), 378389.

2. Grznar, P., Gregor, M., Krajcovic, M., Mozol, S., Schickerle, M., Vavrik, V., Durica, L., Marschall, M., Bielik, T. (2020). Modeling and simulation of processes in a factory of the future. Applied Sciences-Basel, 10(13), 4503.

3. Kliment, M., Popovic, R., Janek, J. (2014). Analysis of the production process in the selected company and proposal a possible model optimization through plm software module tecnomatix plant simulation. In F. Trebuna (Eds.), Proceedings of 6th Conference on Modelling of Mechanical and Mechatronic Systems (MMaMS) (pp. 221-226). Vysoke Tatry.

4. Karaulova, T., Papstel, J. (2004). Software tools for modelling and simulation of manufacturing processes. In J. Papstel \& B. Katalinic (Eds.), Proceedings of the 4th International Conference of DAAAM National Estonia (pp. 245-248). Tallinn.

5. Hrehova, S., Vagaska, A. (2018). Design of study support to get skills in plant simulation tecnomatix enviroment. In LG. Chova, AL. Martinez \& IC. Torres (Eds.), Proceedings of 12th International Technology, Education and Development Conference (Inted) (pp. 7942-7945). Valencia: INTED.

6. Krajcovic, M. et al. (2004). Priemyselna logistika. Zilina: EDIS.

7. Plinta, D., Hromada, J. (2000). Modelowanie i symulacja systemów produkcyjnych. Bielsko-Biala: Wydawnictwo Politechniki Lódzkiej Filii w Bielsku-Bialej.

8. Scott, G., Suler, P., Kliestik, T., Kicova, E. (2019). Industrial big data analytics for cognitive internet of things: Wireless sensor networks, smart computing algorithms, and machine learning techniques. Analysis and Metaphysics, 18, 23-29.

9. Cope, N., Harrod, S., Reed, EW., Wilkinson, SP. (2000). Simulation of manufacturing processes and their real counterparts. In DPF. Moller (Eds.), Proceedings of the 12th European Simulation Symposium (ESS 2000) (pp. 289-292). Hamburg. 
10. Podhorska, I., Valaskova, K., Stehel, V., Kliestik, T. (2019). Possibility of company goodwill valuation: Verification in Slovak and Czech republic. Management \& Marketing. Challenges for the Knowledge Society, 14(3), 338-356.

11. Lyakina, M., Heaphy, W., Konecny, V., Kliestik, T. (2019). Algorithmic governance and technological guidance of connected and autonomous vehicle use: Regulatory policies, traffic liability rules, and ethical dilemmas. Contemporary Readings in Law and Social Justice, 11(2), 15-21.

12. Trettin, C., Lazaroiu, G., Grecu, I., Grecu, G. (2019). The social sustainability of citizen-centered urban governance networks: sensor-based big data applications and real-time decision-making. Geopolitics, History, and International Relations, 11(2), 27-33.

13. Fedorko, G., Molnar, V., Vasil, M. Hanzl, J. (2018). Application of the tecnomatix plant simulation program to modelling the handling of ocean containers using the agv system. Nase More, 65(4), 230-236.

14. Marin, RL. (2010). Extension of the utility of tecnomatix plant simulation software trough the simulation of the morphologic creative method. Proceedings of 16th International Conference the Knowledge-Based Organization: Applied Technical Sciences And Advanced Military Technologies (pp. 429-434). Sibiu.

15. Bohus, Z. (2016, 1. 19.). Technologia point cloud v plant simulation. Sova Digital. Retrieved from: https://sova.sk/technologia-point-cloud-v-plant-simulation/

16. Trebuna, P., Pekarcikova, M., Edl, M. (2019). Digital value stream mapping using the tecnomatix plant simulation software. International Journal of Simulation Modelling, 18(1), 19-32. 